\title{
A interdisciplinaridade na abordagem das questões ambientais
}

\author{
Jane Eyre G.Vieira* \\ Roberto Prado de Morais**
}

\begin{abstract}
Resumo
A era da informação, da ciência e da tecnologia convive com a exclusão de muitos indivíduos do processo decisório, pertencentes às situações de pobreza, desapropriados de sua cultura, trabalho, dignidade e cidadania. $\mathrm{O}$ trabalho aborda a necessidade de construção de um novo paradigma civilizatório, pautado pela ética, e pela racionalidade ambiental, que responda às inquietações teóricas e práticas advindas do processo acelerado de transformações, no qual as instituições, a ciência, o modo de produção e consumo devem ser repensados. Processo no qual uma nova síntese epistemológica interdisciplinar deverá surgir, fruto da reformulação do saber, de uma visão holística e integradora do ambiente, orientados para a sustentabilidade ambiental.

Palavras-chave. interdisciplinaridade, saber ambiental, informação, sustentabilidade.
\end{abstract}

\section{Introdução}

Diante da crescente crise ambiental observada, busca-se modelos e estratégias epistemológicas de apropriação de saberes com vista à construção de um conhecimento que dê conta das respostas aos desafios enfrentados.

* Assistente Social, Especialista em Planejamento Urbano e Ambiental pela Universidade Católica de Goiás, Doutoranda em Ciências Ambientais na Universidade Federal de Goiás, Analista Técnica Social da Caixa Econômica Federal na Gerência de Apoio ao Desenvolvimento Urbano de Goiás e Gerente Administrativa da ONG Moradia e Cidadania/GO.

** Geógrafo, Especialista em Geologia Ambiental, MSc em Geografia Física, Doutorando em Ciências Ambientais na Universidade Federal de Goiás.

Comun. Inf., v. 6, n. 2, p.31-47, jul./dez. 2003 
Numa realidade em que a humanidade encontra-se numa nova etapa civilizatória - a era da informação, da ciência e da tecnologia, como o maior baluarte da força produtiva e, ao mesmo tempo, destrutivaconvive uma civilização com alto grau de cientificidade em contraposição a tantos excluídos do processo decisório, submetidos às situações de pobreza, desapropriados de sua cultura, trabalho, dignidade e cidadania.

Urge a construção de um novo paradigma civilizatório, pautado pela ética e pela racionalidade ambiental, que venha responder às inquietações teóricas e práticas advindas do processo acelerado de transformações de toda ordem, no qual as instituições, a ciência, o modo de produção e consumo devem ser repensados.

Para o enfrentamento da complexidade gerada pelas questões ambientais impostas, nos seus aspectos físicos, sociais, culturais, econômicos e biológicos, uma nova síntese epistemológica interdisciplinar deverá surgir, fruto da reformulação do saber e de uma visão holística e integradora do ambiente, orientadas para os objetivos de um desenvolvimento com base na sustentabilidade ambiental, eqüitativo e duradouro.

Este trabalho pretende suscitar novas reflexões sobre a atuação do pesquisador, do profissional, com o objetivo de contribuir para a consolidação de um novo tempo, no qual as questões ambientais devem ser tratadas sob diferentes olhares, com vistas a resultados efetivos.

Na terceira parte, o trabalho aponta a interdisciplinaridade como caminho para o saber ambiental, superando o conjunto de especializações surgidas da incorporação da dimensão ambiental nas disciplinas tradicionais, para abrir-se ao terreno dos valores éticos, dos conhecimentos práticos e dos saberes tradicionais.

Esse item busca abordar os mecanismos que levaram à disciplinarização do conhecimento, como imposição de uma ordem econômica hegemônica, bem como discorre sobre os níveis de integração das disciplinas, diferenciando-os em intra, multi, inter, pluri e transdisciplinaridade, esta última como uma utopia ambiantal a ser perseguida num mundo sem compartimentação, orientado por um conhecimento científico da natureza, para a construção de um racionalidade ambiental.

Com base nos conceitos e visões apresentados, o texto nos leva a repensar a possibilidade de inclusão da população marginalizada no processo de produção, por meio do manejo descentralizado, integra-

Comun. Inf., v. 6, n. 2, p.31-47, jul./dez. 2003 
do e sustentado dos recursos ambientais, respeitando a diversidade cultural, fortalecendo a sua capacidade de autogestão, que é desenvolvida no entendimento quanto ao saber, à racionalidade e à sustentabilidade ambiental.

Não se pretende esgotar a reflexão. Grande e extenso é o caminho a percorrer rumo a uma atuação interdisciplinar, mas fica aqui uma contribuição para a discussão da temática ambiental sob uma ótica de revisão dos processos e da construção de novos saberes, sob o auspício da comunicação, dentre as diversas áreas do conhecimento que irão concorrer diretamente na construção de um novo paradigma civilizatório.

\section{A crise Ambiental e a construção do saber}

Segundo Novaes (2003), a cada dia as questões ambientais se apresentam como realidade mais preocupante, conseqüência dos padrões insustentáveis de consumo no mundo. O quadro que deparamos no verão de 2003, com dezenas de mortes na Europa, provocadas pelas altas temperaturas, próximas a 40 graus centígrados, incêndios, rios secando, geleiras desmoronando, a mais alta temperatura dos Alpes Suíços em 250 anos, escassez de energia, falta de água, variações climáticas acontecendo, segundo diversos Centros de Pesquisa e estudos de mudanças climáticas, mais rapidamente do que se esperava, não se explica apenas por causas naturais, mas também como conseqüência da ação humana.

Oúltimo relatório Previsão Global 3, também denominado de GEO3, divulgado pelo PNUMA - Programa das Nações Unidas para o Meio Ambiente, em maio de 2002, apresenta um completo raio X da situação da Terra. Os resultados da pesquisa mostram o que mudou no planeta nos últimos trinta anos, contados a partir da Conferência de Estocolmo, demonstrando que o diagnóstico do estágio de degradação ambiental é ruim e os prognósticos são assustadores, requerendo ação conjunta de todos os povos, de forma integrada e tempestiva, para conter o acelerado avanço do aniquilamento dos recursos naturais pela ação do homem.

Nesse contexto, a noção de meio ambiente deve ser multicêntrica, complexa e objeto de diferentes escalas de abordagem (Floriani, 2000: 100). "O meio ambiente - que resulta da interação da sociedade humana com os ecossistemas terrestres - é uma realidade histórica, soci-

Comun. Inf., v. 6, n. 2, p.31-47, jul./dez. 2003 
al, plurifacetada e, por conseguinte, uma realidade interdisciplinar" (Coimbra, 2000: 68).

Na problemática ambiental, os fundamentos teóricos de formas inovadoras da produção do conhecimento científico não poderão ser dissociados da prática interdisciplinar.

As ciências buscam dar conta dos processos reais, por meio da constituição de seus construtos teóricos e de seus arcabouços conceituais. Segundo Leff,

"O conhecimento científico é o processo de produção dos conceitos - da concretude do pensamento - que permite a apreensão cognoscitiva do real. É o objeto das ciências o que, em seu efeito de conhecimento, 'recorta a realidade' a partir de diferentes perspectivas" (LEFF, 200, p. 27).

No âmbito das questões ambientais, a construção do conhecimento científico não se dá num vazio ideológico, e sim num campo de conflitos e contradições, no qual o cientista, como sujeito das ciências e com sua prática de produção do conhecimento estreitamente vinculada a ideologias teóricas, produz o saber.

Nesse espaço ideológico, onde se desenvolve a interdisciplinaridade, tem predominado uma visão naturalista dos processos políticos de dominação, ocultando os processos de reapropriação da natureza ditadas pelas estratégias dominantes da globalização econômica (Leff, 2000:28), com base no reducionismo ecologista e no funcionalismo sistêmico que pensa o homem como objeto das teorias sóciobiológicas.

\section{A interdisciplinaridade na construção do saber ambiental}

As questões ambientais exigem um complexo e integrado arcabouço de conhecimentos que, abstraindo dos paradigmas tradicionais de cada área, erige um novo saber, diferenciado em sua origem quanto ao campo temático de cada ciência.

O saber ambiental está em processo de construção, que não será homogêneo nem um paradigma globalizante do conhecimento, mas calcado na constante problematização deste, implicando a integração interdisciplinar do conhecimento para explicar os sistemas socioambientais complexos, "sem desconhecer as especificidades das diferentes ciências, historicamente construídas, ideologicamente legitimadas e socialmente institucionalizadas" (Leff, 2002:163).

Comun. Inf., v. 6, n. 2, p.31-47, jul./dez. 2003 
Em seu livro Saber Ambiental, Leff afirma que esse tipo de saber excede as "ciências ambientais", como um conjunto de especializações surgidas da incorporação da dimensão ambiental nas disciplinas tradicionais, para abrir-se ao terreno dos valores éticos, dos conhecimentos práticos e dos saberes tradicionais.

\subsection{A disciplinarização do conhecimento}

Antes de partimos para as discussões que permeiam a abordagem e o conceito da interdisciplinaridade, torna-se necessário que se faça uma conceituação do termo disciplina. Segundo Santomé (1998:55), "uma disciplina é uma maneira de organizar e delimitar um território de trabalho, de concentrar a pesquisa e as experiências dentro de um determinado ângulo de visão". Ou seja, oferecer uma imagem particular da realidade que entra no ângulo do seu objetivo.

Na busca da origem primeira do vocábulo disciplina, Alice Ribeiro (1999:176) recorre aos conceitos de Foucault, que analisa o desenvolvimento do poder disciplinar como processos de vigilância e de controle do tempo, do espaço e do corpo, como uma nova forma de dominação surgida para a disciplinarização de sujeitos à época da revolução industrial e a serviço do modo de produção capitalista. Esse processo se estendeu ao processo de disciplinarização dos saberes, que se tornou técnicas de adestramento, "interior ao processo de ensino-aprendizagem e, de certa forma, interior aos próprios sujeitos" (idem:177).

Disciplina, conforme José de Ávila, (2000:55), é o conhecimento assimilado que se aprende e passa a fazer parte da vida; "é o conjunto de conhecimentos científicos, artísticos, lingüísticos etc., que se professam em cada cadeira ou instituto escolar". Lembra, contudo, que a apropriação do vocábulo para a elaboração de currículos escolares empobreceu a semântica, e o esvaziamento do sentido de aprender agravou-se com a fragmentação da cultura e do ensino escolar.

Historicamente, já no início do séc. XIX tem início o desenvolvimento de uma multiplicidade de disciplinas autônomas, o que evidencia uma clara tendência à diferenciação do conhecimento. Esse processo está ligado a transformações sociais na Europa, especialmente em virtude do desenvolvimento industrial, que culminava com a necessidade de uma especialização de acordo com a divisão material do processo de produção vigente. "Paulatinamente surgem numerosas dis-

Comun. Inf., v. 6, n. 2, p.31-47, jul./dez. 2003 
ciplinas científicas que, como conjunto ordenado de conceitos, problemas, métodos e técnicas, organizam nosso pensamento, possibilitando análise e a interação com a realidade" (Santomé, 1998:59).

"As disciplinas nos impõem uma determinada forma de pensar, com as possibilidades e riscos que isso implica" (Idem:59). Segundo Mario Bunje (1986) apud Santomé (1998:59),

\begin{abstract}
"Quanto mais familiarizada uma pessoa estiver com determinada teoria e seu correspondente modo de pensar, mais difícil lhe será adotar uma teoria rival que implique em uma maneira diferente de pensar. Em geral, a posse de conhecimentos proporciona asas em certo aspecto cortando-as em outros".
\end{abstract}

A atomização de tarefas no âmbito dos processos produtivos também passou a ser reproduzido no interior dos sistemas educacionais. Os estudantes e trabalhadores ficaram impossibilitados de intervir nos processos educacionais e produtivos a que se vinculam, enquanto a taylorização na educação impede professores e alunos de participarem da reflexão crítica sobre a realidade (Santomé, 1998:13).

\title{
3.2 A interdisciplinaridade e os níveis de integração das disciplinas
}

De acordo com Frigotto (1995:28), "o trabalho interdisciplinar não se efetiva se não formos capazes de transcender a fragmentação e o plano fenomênico, heranças fortes do empirismo e do positivismo". O referido autor completa frisando ainda uma segunda conseqüência desse processo, que "também não se efetiva se cairmos no reducionismo estruturalista que abandona o plano discursivo".

"As propostas interdisciplinares surgem e desenvolvem-se apoiando nas disciplinas", ou seja, para que haja interdisciplinaridade é preciso haver disciplinas. "A própria riqueza da interdisciplinaridade depende do grau de desenvolvimento atingido pelas disciplinas e estas, por sua vez, serão efetuadas positivamente pelos contatos e colaborações interdisciplinares" (Santomé, 1998:61).

O contexto histórico vivido nessa virada de milênio, caracterizado pela divisão do trabalho intelectual, pela fragmentação do conhecimento e pela excessiva predominância das especializações, demanda a retomada do antigo conceito de interdisciplinaridade, que no longo

Comun. Inf., v. 6, n. 2, p.31-47, jul./dez. 2003 
percurso entre os século XIX e XX foi sufocado pela racionalidade da revolução industrial. A necessidade de romper com a tendência fragmentadora e desarticulada do processo do conhecimento justificase pela compreensão da importância da interação e transformação recíprocas entre as diferentes áreas do saber.

A interdisciplinaridade, como aspiração emergente de superação da racionalidade científica positivista, aparece como entendimento de uma nova forma de institucionalizar a produção do conhecimento nos espaços da pesquisa, na articulação de novos paradigmas curriculares e na comunicação do processo em perceber as várias disciplinas; nas determinações do domínio das investigações, na constituição das linguagens partilhadas, nas pluralidades dos saberes, nas possibilidades de trocas de experiências e nos' modos de realização da parceria.

A interdisciplinaridade não é um campo recente de indagações. Já encontramos manifestações de preocupação com o assunto desde a antiguidade, com a Escola de Alexandria, que pode ser considerada a instituição mais antiga a assumir um compromisso com a integração do conhecimento a partir de uma ótica filosófico-religiosa. Na época clássica, houve também uma aspiração à unidade do saber entre os sofistas e romanos; no século XVII, nomes como Comenio, Comte, Kant, Descartes também mostravam preocupação com o grau de fragmentação do conhecimento; entretanto, no século XVIII, com o movimento dos Enciclopedistas Franceses, a preocupação exacerbou-se. Retomado por Bacon, Leibniz, dentre outros, sofreu o impacto do século XIX com a expansão do trabalho científico e o advento da especialização.

A reorganização do conhecimento é uma das características principais que distingue o século XX dos anteriores. Nota-se que há uma disputa entre a disciplinaridade e a interdisciplinaridade, ambas com adeptos radicais. Observa-se claramente, contudo, que nas últimas décadas a interdisciplinaridade tem adquirido uma maior projeção. Santomé (1998) tece algumas considerações sobre os desafios em se buscar a interdisciplinaridade do conhecimento:

"A ruptura de fronteiras entre as disciplinas (corolário da multidisciplinaridade de áreas científicas e de modelos de sociedade cada vez mais abertos, do desaparecimento de barreiras na comunicação e de uma universalização da informática) está levando à consideração de modelos de análise muito

Comun. Inf., v. 6, n. 2, p.31-47, jul./dez. 2003 
mais potentes dos que caracterizavam apenas uma especialização disciplinar" (Idem: 44).

"Também é preciso frisar que apostar na interdisciplinaridade significa defender um novo tipo de pessoa, mais aberta mais flexível, solidária, democrática, e crítica. $\mathrm{O}$ mundo atual precisa de pessoas com uma formação cada vez mais polivalente para enfrentar uma sociedade na qual a palavra mudança é um dos vocábulos mais freqüentes e onde o futuro tem um grau de imprevisibilidade como nunca em outra época da história da humanidade" (Idem: 45).

Frigoto (1995:45) aponta também algumas dificuldades para se tratar a interdisciplinaridade como processo pedagógico. "Se no campo da produção científica os desafios do trabalho interdisciplinar são grandes, quando passamos para o cotidiano do trabalho pedagógico percebemos que estamos diante de limites cruciais".

De acordo com Leff,

"A interdisciplinaridade ambiental estabelece a transformação dos paradigmas estabelecidos do conhecimento para internalizar um saber ambiental. (...) a complexidade se abre para um diálogo de saberes que acarreta uma abertura à racionalidade que vai da solidariedade e complementaridade entre disciplinas ao antagonismo de saberes; onde se relacionam processos significativos, mais que posições cientificas, interesses disciplinares e verdades objetivas" (LEFF, 2000, p. 30).

Existe uma preocupação em definir terminologias a respeito do entorno interdisciplinar, apesar de as definições se baseiarem em diferentes pressupostos. Os cinco níveis abaixo definidos são os mais utilizados na bibliografia especializada sobre o assunto, como salienta Japiassu (1976): “(...) existe uma gradação entre esses conceitos, gradação essa que se estabelece ao nivel de coordenação e cooperação entre as disciplinas".

Assim, a relação entre as disciplinas recebe um nome específico, de acordo com a quantidade da integração existente entre elas, como, por exemplo, intra, multi, pluri, inter, ou transdisciplinaridade).

Comun. Inf., v. 6, n. 2, p.31-47, jul./dez. 2003 
Com essa classificação é possível elaborar uma síntese próxima ao consenso sobre os diversos conceitos. Entende-se por intradisciplinaridade o aprofundamento de um aspecto inerente a uma determinada ciência; multidisciplinaridade se caracteriza por uma superposição de disciplinas que não estabelecem relação aparente; a pluridisciplinaridade consiste na superposição de disciplinas cujo objeto é correlato, em outras palavras, sugere a possibilidade da ocorrência de relação entre elas; a interdisciplinaridade indica a existência de intercâmbio por parte de duas ou mais disciplinas, sem levar em conta o modo como ele ocorre, pois a constatação e a classificação são suficientes; por fim, a transdisciplinaridade como um saber holístico e integrador, sem falhas nem lacunas, "um conhecimento reunificador que transcende o propósito de estabelecer pontes interdisciplinares entre ilhotas científicas isoladas" (Leff, 2000:32).

A conceituação que envolve o termo interdisciplinaridade não é muito clara e verifica-se em diversos autores que não existe um consenso que envolva sua definição numa abordagem comum. Segundo Santomé(1998:45),

\begin{abstract}
"Para algumas pessoas, a interdisciplinaridade tem sua razão de ser na busca de uma grande teoria, uma nova etapa do desenvolvimento da ciência caracterizado por uma reunificação dos saberes, um modelo que possa ser aplicado a todos os âmbitos atuais do conhecimento. Para outras, o caminho rumo a maiores parcelas de interdisciplinaridade é provocado pela dificuldade, que se torna mais evidente a cada dia, de delimitar as questões que são objeto deste ou daquele campo de especialização do saber. Atualmente, a delimitação das respectivas fronteiras é uma disputa em muitas áreas do conhecimento".
\end{abstract}

Finalmente, pode-se dizer ainda que a interdisciplinaridade deve ainda ser encarada como

“(..) um objetivo nunca completamente alcançado e que por
isto deve ser permanentemente buscado. Não apenas uma
proposta teórica, mas sobretudo uma prática. (...), é ainda
uma condição necessária para a pesquisa e a criação de mo-
delos mais explicativos desta realidade tão complexa e difícil
de abranger”. (Idem: 66).

Comun. Inf., v. 6, n. 2, p.31-47, jul./dez. 2003 


\section{Abordagem integrada na gestão ambiental}

Conforme abordado, o saber ambiental orienta a aplicação de conhecimentos em diversos setores, promovendo uma hibridização das ciências com o campo de saberes "tradicionais", populares e locais (Leff, 2000:45). A produção interdisciplinar de conhecimentos compartilha dessa filosofia, engendrando processos integrados de busca da autonomia cultural, autogestão dos recursos pelas comunidades, pela disseminação e aplicação de conhecimentos que favoreçam a apropriação coletiva dos recursos naturais, a gestão democrática e a divisão eqüitativa dos custos e benefícios.

Apesar do efeito mobilizador exercido pelas conferências internacionais, em especial a Rio 92, as ações empreendidas em nome da gestão ambiental se apresentam, em sua maioria " "ambíguas, fragmentadas e pouco capazes de fazer justiça à complexidade dos desafios criados pela busca da redução das desigualdades no interior de cada país e entre países" (Vieira in Leff, 2002: 9).

A gestão ambiental participativa para a apropriação social da natureza pressupõe uma transição democrática e a possibilidade de inclusão da população marginalizada no processo de produção por meio do manejo descentralizado, integrado e sustentado dos recursos ambientais, respeitando a diversidade cultural e fortalecendo a sua capacidade de autogestão.

Para dar conta das novas realidades torna-se impositiva a junção de esforços, a construção do conhecimento coletivo em torno das questões ambientais que nos envolvem, por meio de estratégias como a capacitação para a gestão ambiental.

“Gestão ambiental, portanto, é vista aqui como o processo de mediação de interesses e conflitos (potencial ou explícitos) entre atores sociais que agem sobre os meios fisico-natural $\mathrm{e}$ construído, objetivando garantir o direito ao meio ambiente ecologicamente equilibrado, conforme determina a Constituição Federal" (QUINTAS, 2001, p. 145).

\subsection{O saber e a racionalidade ambiental}

O processo civilizatório contemporâneo, calcado na racionalidade econômica, gera processos complexos para os quais as ciências, como disciplinas, não apresentam explicação. Produz um espaço de exclu-

Comun. Inf., v. 6, n. 2, p.31-47, jul./dez. 2003 
são social e cultural e externalidades ambientais como resultado da desvalorização da natureza, da superexploração, degradação e desintegração dos recursos naturais, sem a devida internalização dos prejuízos causados pelos processos de produção e consumo.

Essa perspectiva de busca de alternativas para dar respostas às questões ambientais, nas quais a entropia dos processos produtivos tecnológicos é orientada pela lógica do mercado, cria a necessidade de uma abordagem que integre diversos conhecimentos, na expectativa de romper com os limites de cada disciplina e com os paradigmas científicos dominantes, avançando para uma abordagem holística e interdisciplinar do saber.

O saber ambiental, contudo não implica no logocentrismo homogeinizante, mas na constituição de um espaço de racionalidade que incorpore, de forma inter e transdisciplinar, o heterogêneo, as práticas tradicionais, as ciências que dão suporte à construção de um desenvolvimento com sustentabilidade ambiental. Como afirma Leff, "desta maneira, o saber ambiental transforma o campo do conhecimento gerando novos objetos interdisciplinares (...) novos processos sociais de objetivação onde se constrói a racionalidade ambiental" (Leff, 2001:151).

Perpassa, ainda, pela reflexão da ciência em ação e da prática profissional, no sentido de melhorar os processos nos quais haja coerência na aplicação dos saberes construídos, da prática e dos resultados a serem alcançados, num esforço de integração, de interdisciplinaridade em constante avaliação. Como afirma Schõn,

"El desarrollo de la ciência en acción no puede lograrse por investigadores que se mantienen al margen de los contextos de la acción, ni por profesionales que tienen limitado su tiempo, o su inclinación o competencia respecto a la reflexión sistemática. Su desarrollo requerirá nuevos caminos de integración de la investigación y la práctica reflexivas" (SCHÕN, 1998, p. 281).

A racionalidade ambiental emerge da necessidade de se repensar o processo insustentável imposto pela racionalidade econômica vigente, propondo uma alternativa para a racionalidade social e produtiva; surge da confluência de interesses e práticas sociais e se concretiza numa inter-relação permanente entre teoria e práxis. De acordo com Leff, autor que norteia este debate,

Comun. Inf., v. 6, n. 2, p.31-47, jul./dez. 2003 
“(...) a racionalidade ambiental não é a expressão de uma lógica, mas o efeito de um conjunto de interesses e de práticas sociais que articulam ordens materiais diversas que dão sentido e organizam processos sociais através de certas regras, meios e fins socialmente construídos.'Estes processos especificam o campo das contradições e relações entre a lógica do capital e as leis biológicas; entre a dinâmica dos processos ecológicos e as transformações dos sistemas socioambientais" (LEFF, 2001, p. 134).

Para esse autor, a racionalidade ambiental se constrói mediante a articulação de quatro esferas de racionalidade. Uma racionalidade substantiva, que define os valores e os objetivos que orientam as ações sociais, como a eqüidade social, a diversidade cultural, a democracia e a sustentabilidade ecológica; uma racionalidade teórica, que sistematiza os valores da racionalidade substantiva, orientando uma teoria crítica da produção e do desenvolvimento sustentável; uma racionalidade instrumental, que coloca em prática os princípios do desenvolvimento sustentável com instrumentos para implementar projetos de gestão ambiental; e uma racionalidade cultural, derivada da diversidade estabelecida pela racionalidade substantiva, que concebe a sociedade como uma composição multiétnica, implicando na participação das comunidades na percepção, gestão e manejo de seus recursos, todas orientadas para a constituição de uma racionalidade ambiental e a transição para um futuro sustentável.

\subsection{Sustentabilidade ambiental: uma crítica ao desenvolvimento sustentável}

Especialmente na última década, os problemas ambientais passaram a figurar como uma questão política, na qual os conflitos socioambientais implicam questões éticas; lutas pela apropriação dos recursos da natureza, com resultados como a degradação ambiental; a pobreza e a exploração do próprio homem, gerando a acumulação do capital e, conseqüentemente, as desigualdades sociais, a perda de valores e práticas socioculturais, dentre outras externalidades que não são consideradas no processo.

Segundo Leff, a retórica do desenvolvimento sustentável gera uma metástase do pensamento crítico, acomodando numa mesma versão as contradições entre produção, riqueza e acumulação do capital; e a

Comun. Inf., v. 6, n. 2, p.31-47, jul./dez. 2003 
reversão das leis de entropia, valorização e reintegração do ambiente, e sua recodificação como elemento do capital globalizado e da ecologia generalizada. Para ele, esse processo mostra o capital, em sua fase ecológica, passando das formas tradicionais de apropriação primitiva e selvagem dos recursos naturais para uma nova estratégia que legitima a apropriação econômica da biodiversidade como patrimônio comum da humanidade, num discurso de racionalidade globalizante e homogeneizante, reduzindo o ambiente à razão econômica.

O discurso do desenvolvimento sustentável está presente nos meios institucionais, acadêmicos e políticos, contudo, ainda não se vislum- brou um paradigma teórico e um processo de pesquisa acabado. Segundo Leff, a economia ecológica questiona os fundamentos da economia vigente sem cortar os laços que a prende à economia neoclássica dos recursos naturais, incluindo, em sua concepção de ambiente, os limites entrópicos e a internalização dos custos, sem, contudo, considerar a natureza como um potencial ecológico a ser gerido com formas alternativas de desenvolvimento que assegurem a sobrevivência e um futuro para toda a humanidade.

Os caminhos apontados por muitos cientistas e ambientalistas são a atribuição de valores econômicos aos recursos naturais, com sua incorporação nas contas nacionais, e a compensação justa para os governos e comunidades do Terceiro Mundo quanto à exploração dos negócios vinculados à biodiversidade, como parte do jogo da globalização.

Nessa ótica, quando se fala de sustentabilidade é preciso considerar os custos externos das atividades econômicas, que devem ser progressivamente internalizados, instituindo uma combinação de penalidades e prêmios, e de regulamentação, num esforço para conter a degradação ambiental.

No entanto, a sustentabilidadade não será alcançada somente pela distribuição eqüitativa dos custos e benefícios constituídos por essas externalidades. Essa sujeição à racionalidade econômico-tecnológica, sob o valor unidimensional do mercado, não conseguirá responder às necessidades requeridas para uma sociedade sustentável.

Nesse sentido, há que se ter, como referencial para a execução de projetos educativos interdisciplinares, com vistas a desenvolver a consciência ambiental das comunidades, que uma educação que não leve em consideração a racionalidade ambiental, e que não questione os padrões irracionais de consumo induz a um estilo de vida

Comun. Inf., v. 6, n. 2, p.31-47, jul./dez. 2003 
descompro-metido com a sustentabilidade, tornando inócuos os esforços nas ações corretivas da degradação ambiental, e com efeito de curta duração o fato de se capitalizar a natureza, já que a ênfase é muito mais para a atribução de valores econômicos aos recursos naturais do que observar os seus limites ecológicos e entrópicos, premissa indispensável para a sustentabilidade (Vieira, 2002:66/ 67). Portanto, afirma Leff,

\begin{abstract}
“(...) a racionalidade ambiental não é a extensão da lógica do mercado à capitalização da natureza, mas a resultante de um conjunto de significações, normas, valores, interesses e ações socioculturais; (....) implica, pois, além de um equilíbrio entre crescimento econômico e conservação da natureza, a possibilidade de mobilizar o potencial ecotecnológico, a criatividade cultural e a participação social para construir formas diversas de um desenvolvimento sustentável, igualitário, descentralizado e autogestionário, capaz de satisfazer as necessidades básicas das populações, respeitando sua diversidade cultural, melhorando sua qualidade de vida. Isto implica a transformação dos processos de produção, dos valores sociais e das relações de poder para construir uma nova racionalidade produtiva com a gestão participativa da cidadania"(LEFF, 2001, p. 143/86).
\end{abstract}

\title{
5 Considerações Finais
}

Trabalhar a questão ambiental em todos os seus aspectos constitui um espaço de aprendizado e de exercício teórico e prático da interdisciplinaridade.

Diante dos crescentes problemas ambientais, impostos pelo modo de produção e consumo da sociedade contemporânea, a interdisciplinaridade desponta como uma metodologia indispensável à abordagem e ao enfrentamento dos desafios ambientais.

Não basta a ampliação das diversas áreas do conhecimento pela interação das diferentes disciplinas e saberes, mas também as interfaces entre diversos setores da sociedade e do poder público. A interdisciplinaridade se dará como filosofia de trabalho, que, além do meio científico e das práticas populares, também despontará para a interinstitucionalidade, conectando conhecimento e ações à natureza holística do universo (Coimbra, 2000:67).

Comun. Inf., v. 6, n. 2, p.31-47, jul./dez. 2003 
Para a prática interdisciplinar, torna-se necessário um constante exercício de atitudes receptivas mentais, sociais, éticas, um desejo de avançar no conhecimento e nos resultados, e um esforço para transitar entre as diferentes formas de aquisição de conhecimentos. Não é um conhecimento adquirido na escola tradicional, e sim a abertura para novos valores, novos modelos que ampliem a visão do objeto de estudo, que será condição para a integração de saberes.

Tanto a pesquisa acadêmica quanto os projetos desenvolvidos pelos órgãos públicos de gestão local ou regional requerem a ruptura das visões compartimentadas em favor da abordagem interdisciplinar. Tornase condição para o alcance de resultados efetivos das pesquisas e projetos, a junção de diferentes áreas do conhecimento, a busca da participação social na gestão ambiental, utilizando metodologias de disseminação do saber e da gestão participativa na tomada de decisões.

Uma abordagem sistêmica das questões que comprometem a vida no planeta transcende o espaço acadêmico para todos os campos nos quais se desenvolve a ação vinculada aos processos humanos que impactam os ecossistemas terrestres.

No campo das ciências,

\begin{abstract}
“A questão ambiental gera o processo de fertilizações transdisciplinares por meio da transposição de conceitos e métodos entre diferentes campos do conhecimento. Nesse processo vai se definindo o 'ambiental' de cada ciência centrada em seu objeto de conhecimento, que leva à sua transformação para internalizar o saber ambiental que emerge em seu entorno. São estes corpos transformados de conhecimento os que se estendem para uma articulação interdisciplinar do saber ambiental. (...) O saber ambiental vai se limitando e concretizando em torno de cada uma das ciências e das disciplinas constituídas" (LEFF, 2002, p. 165/67).
\end{abstract}

Profissionais, pesquisadores, gestores públicos e cidadãos comuns são sujeitos na construção de uma nova racionalidade ambiental, na qual desponta uma sociedade capaz de repensar o seu modo de vida e prospectar o seu futuro com base nas ações presentes: uma utopia necessária a ser perseguida.

Comun. Inf., v. 6, n. 2, p.31-47, jul./dez. 2003 


\begin{abstract}
The era of information, science and technology lives together with the exclusion of so many people of the decision process, belonging to the poverty situations, dispossessed of their cultures, work, dignity and citizenship. The work approaches the needing of construction of a new civilization's paradigm, ruled in the ethics, in the environmental rationality, that answers to the theoretical and practical inquietudes succeeded of the accelerated process of transformations, where the institutions, the science, the production way and consumption should be rethought. Where a new interdisciplinary knowledge theory synthesis should appear, result of the knowledge changing, of a vision holistic and integrated of the atmosphere, guided for the environmental sustainability.

Key words: interdisciplinary, to know environmental, information, sustainability
\end{abstract}

\title{
Referências
}

COIMBRA, J. A. A. Considerações sobre a interdisciplinaridade. In: PHILIPPI, A. Jr. et al. Interdisciplinaridade em ciências ambientais. São Paulo: Signus Editora, 2000.

FAZENDA, I. C. A. Integração e interdisciplinaridade no ensino brasileiro. São Paulo: Edições Loyola, 1993.

FLORIANI, D. Marcos conceituais para o desenvolvimento da interdisciplinaridade. In: PHILIPPI, A. Jr. et al. Interdisciplinaridade em ciências ambientais. São Paulo: Signus Editora, 2000.

FRIGOTTO, G. A interdisciplinaridade como necessidade e como problema nas ciências sociais. In: JANTTSHE, A. P.; BIANCHETTI, L. (Org.). . Interdisciplinaridade: para além da filosofia do sujeito. 5. ed. Petrópolis: Vozes, 1995. p. 25-49.

JAPIASSÚ, H. Interdisciplinaridade e patologia do saber. Rio de Janeiro: Imago, 1976.

LEFF, E. Complexidade interdisciplinar e saber ambiental. In: PHILIPPI, A. Jr. et al. Interdisciplinaridade em ciências ambientais. São Paulo: Signus Editora, 2000.

. Epistemologia ambiental. 2. ed. São Paulo: Cortez, 2002.

. Saber ambiental: sustentabilidade, racionalidade, complexidade e poder. Petrópolis: Vozes, 2001.

LOPES, A. R. C. Conhecimento escolar: ciências e cotidiano. Rio de Janeiro: EdUERJ, 1999.

NOVAES, W. Opinião. Jornal O Popular. Goiânia, 14 out. 2003.

PNUMA. G. 3 - Global Environment: United Nations Environment Programme, [S.1.:s.n], 2002. Disponível em: <http: // www.earthprint.com>. Acesso em 23 ago. 2002.

Comun. Inf., v. 6, n. 2, p.31-47, jul./dez. 2003 
QUINTAS, J. S. Gestão Ambiental. In: LEITE, A.; MEDINA, N. M. Educação ambiental: a educação e educação ambiental I. 2. ed. Brasília: MMA, 2001. v.5, p. 145.

SANTOMÉ, J. T. Globalização e interdisciplinariedade: o currículo integrado. Porto Alegre: Artes Médicas, 1998.

SCHÕN, D. A. EI profesional reflexivo: cómo piensan los profesionales cuando actúan. Buenos Aires: Paidó, 1998.

VIEIRA, J. E. G. Educação para a sustentabilidade: um pressuposto da participação comunitária na gestão ambiental nas cidades. In: Serviço social e sociedade. São Paulo: Cortez, ano XXIII, n. 72, 2002.

Comun. Inf., v. 6, n. 2, p.31-47, jul./dez. 2003 